\title{
Evaluation of the behavior of an innovative thermally activated building system (TABS) with PCM for an efficient design
}

\author{
MCarmen Guerrero ${ }^{1 *}$, José Sánchez ${ }^{1}$, Servando Álvarez ${ }^{1}$, José Antonio Tenorio ${ }^{2}$, Luisa F. Cabeza ${ }^{3}$, Cesar Bartolomé ${ }^{4}$ \\ MCarmen Pavón ${ }^{1}$ \\ ${ }^{1}$ Grupo de Termotecnia, Universidad de Sevilla, Escuela de Ingenieros Camino de los Descubrimientos s/n. 41092, \\ Seville, Spain. \\ ${ }^{2}$ Instituto de Ciencias de la Construcción Eduardo Torroja - CSIC, Serrano Galvache 4, 28033 Madrid, Spain. \\ ${ }^{3}$ GREiA Research Centre, INSPIRES Research Centre, Universitat de Lleida, Pere de Cabrera s/n, 25001 Lleida, Spain. \\ ${ }^{4}$ IECA, Instituto Español del Cemento y sus Aplicaciones, Calle de José Abascal 53, 28003 Madrid, Spain
}

\begin{abstract}
The global energy crisis has caused a double effect. On the one hand, users are increasingly aware of the energy cost they face. On the other hand, public administrations have become aware of the importance of limiting energy consumption in buildings as a way to combat climate change and reduce the energy dependence with the climate. This situation supposes a great opportunity for innovative constructive solutions with an energetic behaviour that surpasses the traditional approach of reduction of the transmittance. In this work, studies are presented to obtain potential of a new solution thermally activated with two innovations with respect to those existing in the market: its activation is done by hot / cold water produced by renewable systems; and its concrete structural element in addition to having coupled the heat exchanger presents an innovative mortar doped with PCM microencapsulated phase change material.
\end{abstract}

\section{Introduction}

Without energy, hardly anything would work in this modern era. It is present in every aspect of our lives and, as a consequence, increasing energy efficiency and savings is paramount in our battle against climate change, which will eventually take place in the whole world. An efficient use of energy should be accomplished not only by considering the technologies that produce it, but also the final energy uses. The ongoing progress, that it is facing towards unsustainability, can only be mitigated by changing our way of thinking, modifying normative, promoting education and developing new energy models.

Nowadays, it is impossible to imagine the world as it is known without an electricity supply, every day that passes the electricity consumption grows as our needs do. However, a global growth in consumption leads to a greater need for electricity generation, which in most cases is obtained from fossil fuels, sources limited in nature and which are also the cause of large emissions of harmful gases for the environment [1]. In recent times, it has shown that traditional energy improvement approaches are insufficient to ensure a sustainable future for all, even with the notorious emergence of renewable energies.

In this context, strategies that, they promote reduction of heating and cooling needs through improving thermal comfort and energy savings in buildings like thermal energy storage (TES) or thermal activally building systems (TABS), have been increased their applicability [2].

The implementation of thermal storage techniques improves energy efficiency of buildings by reducing peak needs (costs) and decouple building needs of production systems. They also favor the integration of renewable sources and the possibility of efficient energy management [3]-[5].
Besides, according to [6], structural thermal energy storage intends to activate the thermal mass so as to increase its use on top of its passive behavior to store energy, allowing an interesting potential in a smart grid context where moving loads contributes to increasing flexibility for the grid through demand response approaches. The previous study also claims that since this approach is exploiting the mass of a material that has been built for another purpose, it does not require additional investment in storage devices.

However, although providing energy flexibility in buildings by controlling appliances may be beneficial, from our point of view TCLs should be considered as a higher priority due to their much larger energy consumptions and thus potential contributions. The TCL are able to provide flexibility thanks to the thermal mass and inertia, can be seen as a storage solution that can be controlled.

In [7] different thermal storage options were reviewed, concluding that the incorporated thermal mass was more profitable than the water buffer tanks. Therefore, it is important to take into account the characteristics of the building. The objective in [8] was to assess the potential of buildings to modulate heating power and define simple control strategies to exploit the potential for flexibility. According to [9] which evaluated value of the flexibility of thermal inertia in buildings and active TES in ACS tanks, valuing the participation of users. In addition, the study in [7] presents a review of the existing literature on supervisory control to improve the energy flexibility provided by building heat pumps.

This work shows an innovative solution TABS activated using water tubes. Also commented advantages, this solution has high thermal inertia for guarantee energy and cost savings [5], [10].

Furthermore, heat radiated by these elements improves the comfort conditions (medium term) by improving internal thermal distribution, which is a competitive

\footnotetext{
${ }^{*}$ Corresponding author: mgdelgado@us.es
} 
advantage compared to conventional convective systems [11]-[13].

This work has been done in INPHASE project. The main objective of INPHASE is to develop a new prefabricated panel for facades of residential buildings (dwellings, hotels, university residences, nursing homes, etc.) executed in an industrialized way with conventional systems that have a high thermal inertia. In order to achieve this goal, integration of concrete and phase change materials (PCMs) is carried out. This newly developed construction solution can integrate the phase change materials, either in the concrete matrix or in the constructive solution outside the matrix of this material. Another barrier that this work has allowed to overcome is how to design the activation system that, through a strategic and homogeneous distribution of phase change materials, allows its activation in a period of time short enough to allow its loading and unloading in 24-hour cycles.

\section{Description of studied thermally activated building system (TABS) INPHASE}

The solution studied consists in a new prefabricated panel activated thermally (TABS) for facades of residential buildings. This is composed of concrete as a structural element, which is coupled with a mortar layer and microencapsulated PCM. The layer of mortar and microencapsulated PCM has embedded an exchanger. Water is circulated through this exchanger at different temperatures, depending on thermal needs of building, or availability of renewable energy.

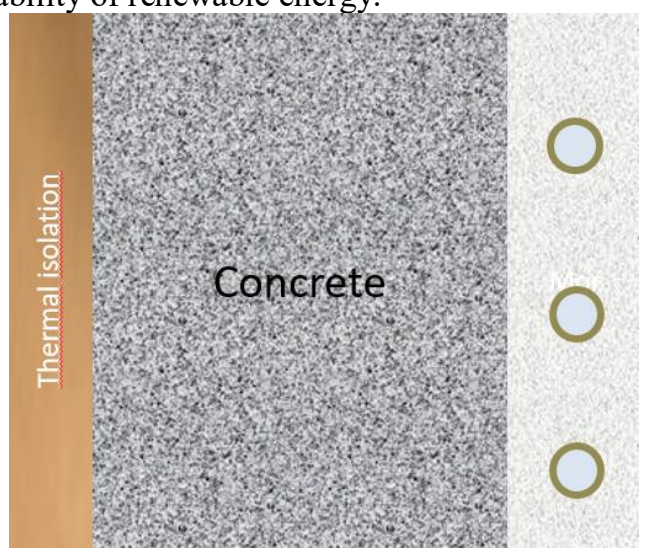

Fig. 1. Internal details of INPHASE solutions

Figure 1 shows main section of the element. It is composed of two layer: layer 1 is concrete $(12 \mathrm{~cm})$ and layer tow is mortar plus microencapsulated PCM $(4 \mathrm{~cm})$. As the PCM is microencapsulated convection currents in the molten PCM is not considered.

Heat exchanger (figure 2) consists of a plastic pipe with an outer diameter of $10 \mathrm{~mm}$ and a thickness of $1 \mathrm{~mm}$ for a panel of $2.7 \times 2.7 \mathrm{~m}$ and $4 \mathrm{~cm}$ of thickness, with a separation of $100 \mathrm{~mm}$ between pipes and a radius of 150 $\mathrm{mm}$ in each elbow. This one, as it has been commented previously, is embedded in the layer of mortar and PCM.

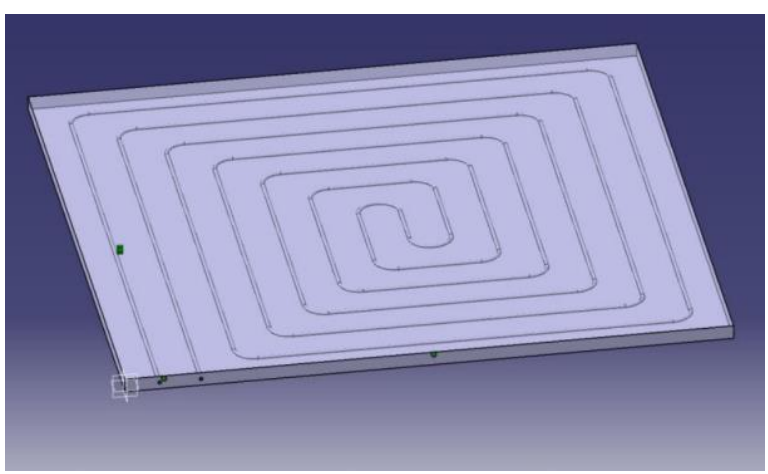

Fig 2. Spiral heat exchanger inside PCM mortar layer

The innovative element of the solution is the mortar on which the pipe grid is fixed and also phase change material is added. Mortar is obtained from cement mixture (CEM I 52.5 R), fine aggregate, limestone filler and microencapsulated Micronal DS 5038X.

The presented constructive solution, which has been developed within the INPHASE project, presents innovative points among which stand out: high thermal inertia, given that the solution is mainly composed of concrete and also micro-encapsulated PCM is added. High thermal activation capacity, given the activation by water through pipe system and optimization of the proposed design for its coupling with a renewable generation system. It should also be noted that the solution has completed the entire value chain and technical tests that require its commercialization.

It should be noted that it is an economically competitive solution, whose global construction costs do not increase with respect to traditional construction, so that the solution developed is commercially viable. In addition, it has been taken into account that the extra costs incurred can be transferred to the product via added value, so that the solution developed allows to gain market share and generate profits. This added value is evident in the analysis made in the following sections.

\section{Analysis of thermal behaviour of proposed solution through CFD}

\subsection{Model of solution}

The modeling consists of generating a reliable geometry with the designed solution, and then mallaring it for its simulation. The geometric model is realized in CATIA software [14]. Figure 3 shows a conceptual scheme of geometry generated.

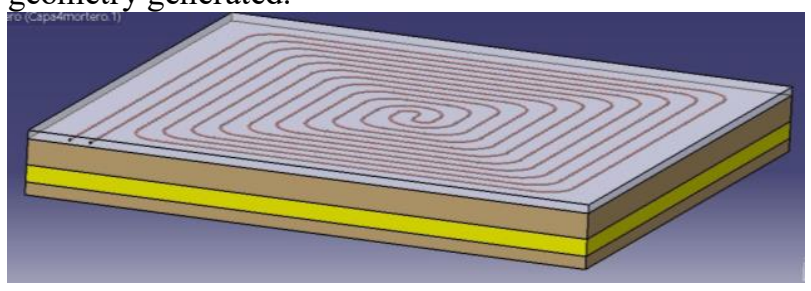

Fig. 3 Model of INPHASE solution using CATIA

Once the solution is geometrically modeled, it is exported to the Ansys Fluent energy simulation tool. The 
mesh is defined in the Meshing of ANSYS program [15] (Figure 4).

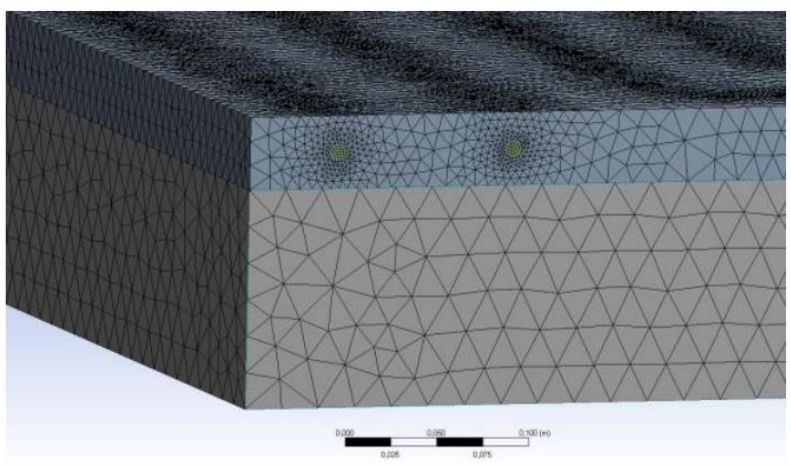

Fig. 4. Mesh of INPHASE solution

The boundary conditions established in the CFD model are the following:

-Adiabatic element on all sides except the wall in contact with the interior space.

-Heat transfer by convection with the indoor environment: $\mathrm{Ta}=20^{\circ} \mathrm{C}$ and heat transfer coefficient $\mathrm{h}=$ $7.5 \mathrm{~W} / \mathrm{m} 2 \mathrm{~K}$.

The model adopted for the study is k-epsilon realizable and time step size has been defined in 10 seconds.

\subsection{Thermal characterization of PCM}

The two most commonly used ways to deal numerically with solution of phase change problems are: "effective thermal capacity" and "enthalpy" [16] .In the present work, the solution of effective thermal capacity was proposed.

The method of effective thermal capacity consists in considering that the thermal capacity of the material is variable with temperature. When the material is at the temperature of phase change, the specific heat of the material increases to a level such that the energy needed to change the temperature in a $\Delta \mathrm{T}$ is equal to the energy necessary for the material to change phase.

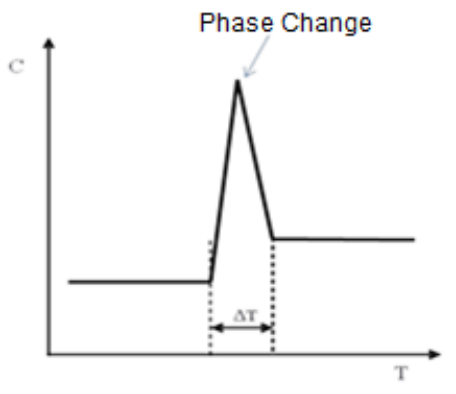

Fig. 5. Characterization of thermal capacity as a function of temperature for effective thermal capacity method

The modeling of behavior of the mortar layer and microencapsulated PCM is based on solution of effective thermal capacity and will consist of a curve of variation of the specific heat of material as a function of temperature. This curve will vary depending on amount of phase change material that has been added inside the mortar layer, according to figure 6 :

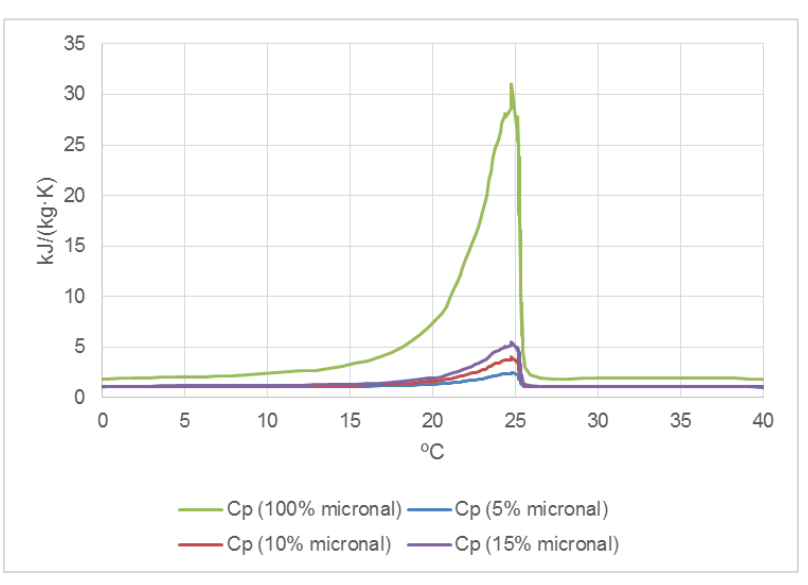

Fig. 6. Model of mortar layer plus PCM

The mathematical formulation of the behaviour of the phase change material is characterized as a variation of the specific heat of the material as a function of the temperature $(\mathrm{T})$ is defined as equation 1 .

\section{Equation 1}

$\begin{array}{ll}(273.2<\mathrm{T}<298) & \mathrm{Cp}(\mathrm{T})=\mathrm{a}_{0}+\mathrm{a}_{1} \cdot \mathrm{T}+\mathrm{a}_{2} \cdot \mathrm{T}^{2}+\mathrm{a}_{3} \cdot \mathrm{T}^{3}+\mathrm{a}_{4} \cdot \mathrm{T}^{4} \\ (\mathrm{~T}>298) & \mathrm{Cp}(\mathrm{T})=\mathrm{f}(\% \mathrm{PCM})\end{array}$

The coefficients $a_{0}, a_{1}, a_{2}, a_{3}$ y $a_{4}$ are adjusted for a case where the entire inner layer is formed by phase change material (100\% PCM) and extrapolation of these coefficients to the analysis cases is done by multiplying each one of them by the percentage of phase change material corresponding to the case to be analyzed.

The specific heat of the material for temperatures higher than $298 \mathrm{~K}$ is formulated in function of the PCM dosage $(. \% \mathrm{PCM})$ as equation 2 :

Equation 2

Specific heat of mortar $=\mathrm{a} 5 \cdot \% \mathrm{PCM}+(1-\% \mathrm{PCM}) \cdot \mathrm{CPM}$

Where as takes a value of $1.8 \mathrm{~kJ} / \mathrm{kg} \cdot \mathrm{K}$ and CPM is the specific heat of mortar and takes a value of $1 \mathrm{~kJ} / \mathrm{kg} \cdot \mathrm{K}$

Table 1. Influence of the PCM dosage percentage on the conductivity of the mortar layer + PCM

\begin{tabular}{|c|c|}
\hline \% dosage PCM & $\begin{array}{c}\text { Conductivity W/mK } \\
\text { (mortar + PCM) }\end{array}$ \\
\hline 0 & 1.8 \\
\hline 5 & 1.71 \\
\hline 10 & 1.63 \\
\hline 15 & 1.54 \\
\hline
\end{tabular}

As shown in table 1, the PCM dosage percentage reduces the conductivity of the layer composed of mortar and PCM, therefore, it is expected in the results of the analysis of the behaviour of the system a reduction of the heat stored in the same.

\section{Sensibility analysis}

In order to analyze efficiency of the solution, a sensitivity analysis is carried out based on the variation of design and operation parameters.

Table 2. Variables for analysis of TABS solution 


\begin{tabular}{|l|l|}
\hline Case & Value \\
\hline $\begin{array}{l}\text { Inlet water temperature Tw } \\
{\left[{ }^{\circ} \mathrm{C}\right]}\end{array}$ & $(30,35,40,45)$ \\
\hline $\begin{array}{l}\text { Dosage of PCM in mortar } \\
\text { slab D [\%] }\end{array}$ & $(0,5,10,15)$ \\
\hline $\begin{array}{l}\text { Duration of charge period P } \\
{[\mathrm{h}]}\end{array}$ & $(6,8,10)$ \\
\hline $\begin{array}{l}\text { Distance between tubes S } \\
{[\mathrm{cm}]}\end{array}$ & $(8,10,12)$ \\
\hline $\begin{array}{l}\text { Duration of cycle } \\
\text { (charge/discharge) }\end{array}$ & $\begin{array}{l}1 \text { charge per day } \\
\text { charge per } \\
\text { two days }\end{array}$ \\
\hline
\end{tabular}

These parameters (table 1) represent main variables that affect thermal performance of the proposed solution, beyond traditional variables and features (transmittance, resistance etc...).

Each of the described cases will be analyzed from efficiency of charging / discharging process. This variable will be obtained from relationship between stored heat $\left[\mathrm{kWh} / \mathrm{m}^{2}\right.$ facade $]$ and maximum storable heat $\left[\mathrm{kWh} / \mathrm{m}^{2}\right.$ facade $]$.

Efficiency is analysis parameter of INPHASE system and represents efficiency of the element as a regenerative exchanger.

To calculate the stored heat, the following variables are computed in the stabilized cycle:

- Heat stored in the concrete and mortar layer is calculated using definition of enthalpy. Heat stored between states is enthalpy difference between states.

- The heat in the mortar layer and phase change material is calculated from definition of mathematical formulation of enthalpy $(\mathrm{Cp}(\mathrm{T}))$.

- The total stored heat will therefore be sum of heat stored in the concrete and mortar.

- The maximum heat potentially stored in concrete is defined as that in which the entire mass of concrete is able to reach the inlet temperature of the water that is circulated through the pipes. Likewise, maximum heat potentially storable in the mortar will be calculated from the enthalpy variation between the water inlet temperature and the reference temperature.

The results obtained by simulation of the described solution are shown below.

\subsection{Results}

As an example, temperature results are extracted for the average case of a solution dosed with $10 \%$ PCM, $10 \mathrm{~cm}$ distance between tubes, charging at constant $40^{\circ} \mathrm{C}$ during $8 \mathrm{~h}$ and discharge of $16 \mathrm{~h}$ (daily cycle). Upper part of figure 7 shows results of concrete temperatures and lower part shows results of mortar zone.

The orange line corresponds to an average zone of the exchanger, blue zone with entrance and gray area as core of the same.

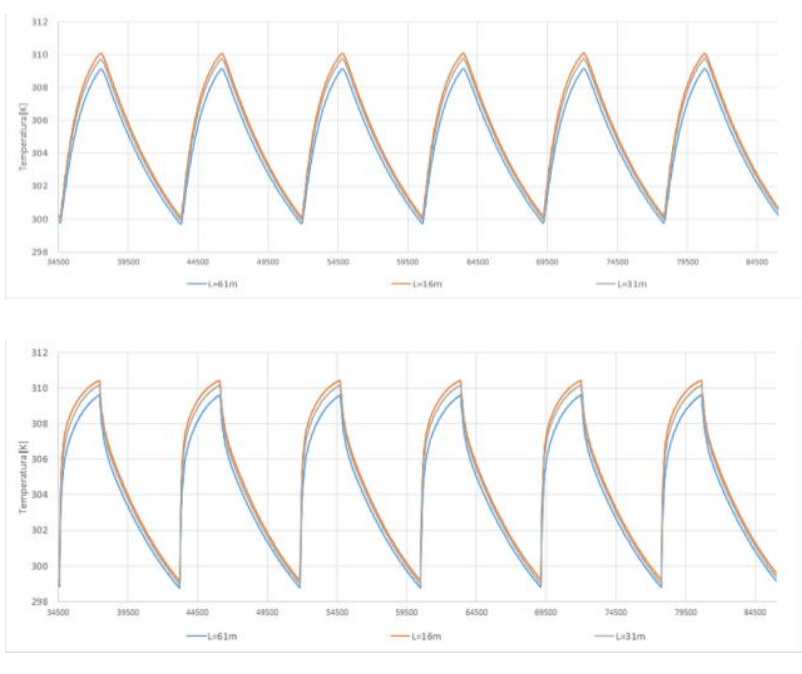

Fig. 7. Temperatures of concrete (top) and mortar (below). Case: $10 \% \mathrm{PCM}, \mathrm{S}=10 \mathrm{~cm}, \mathrm{P}=8 \mathrm{~h}$ and daily cycle

\subsection{Effect of water temperature inlet}

An increase in the temperature of the activation water from $30^{\circ} \mathrm{C}$ to $45^{\circ} \mathrm{C}$ implies an increase in the stored heat and the maximum possible heat to be stored. This implies a process efficiency that varies according to figure 8. In this figure an increase in efficiency of approximately $7 \%$ is observed in the first $5^{\circ} \mathrm{C}$ of water heating and an increase heat stored in the concrete layer. This has been obtained as the specific heat of the concrete by the average temperature difference of the same and a progressive but smaller increase from this temperature. The efficiency is very stable (approximately 50\%) for water inlet temperatures higher than $45^{\circ} \mathrm{C}$.

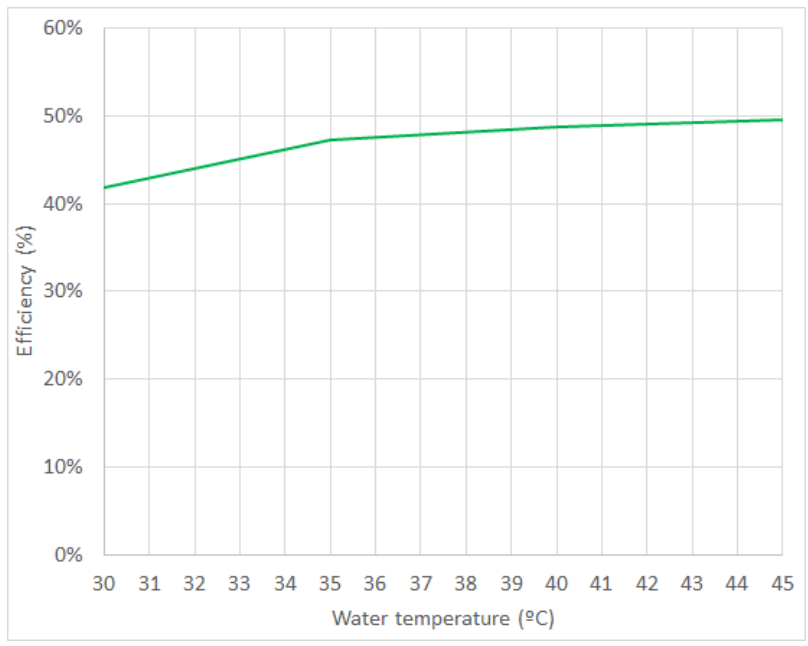

Fig. 8. Variation in storage efficiency with water inlet temperature

\subsection{Effect of PCM dosification}

An increase of the PCM dosage does not imply an increase of the stored heat, since the phase change of the material is not reached. As can be seen in figure 8, the temperature at the end of the discharge / start of the charge has a value of $24.1^{\circ} \mathrm{C}$, not achieving the use of the latent heat of this material. 


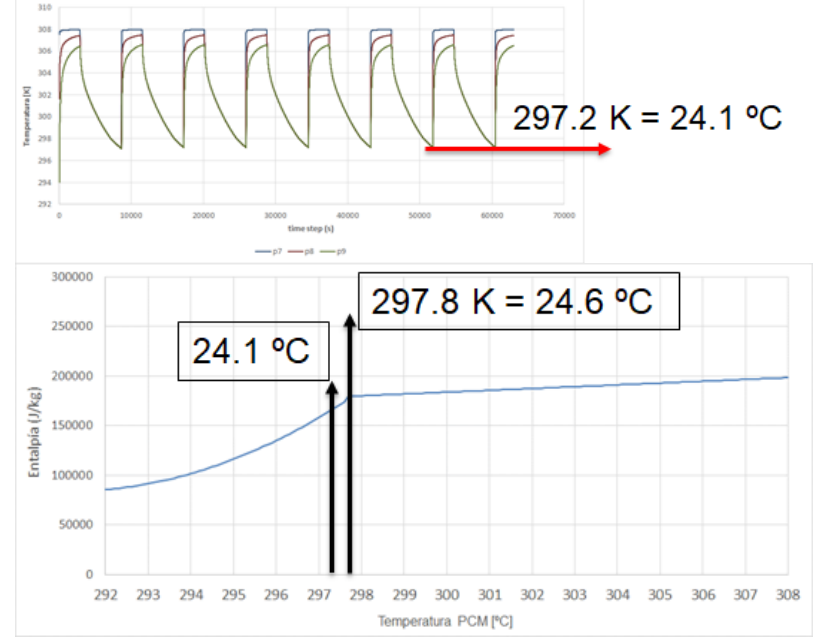

Fig. 9. Evolution of temperatures in a daily cycle.

Likewise, incorporation of phase change material to the proposed solution, increases maximum possible heat to be store. So, efficiency varies according to Figure 10.

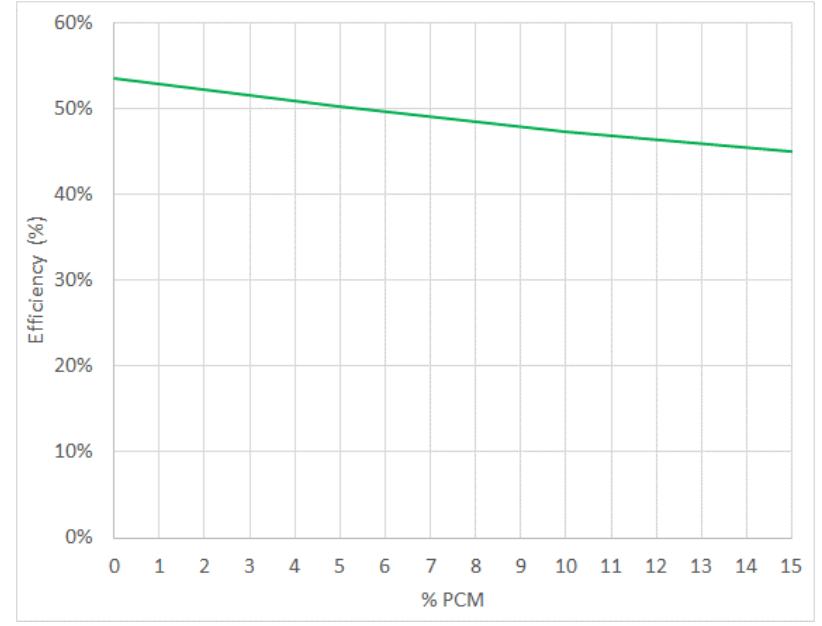

Fig. 10. Variation of storage efficiency with PCM dosage

According figure 10, if solution has $15 \%$ of PCM in mortar layer, it will have an efficiency lower than case without PCM. It is caused by not exploitation of latent energy and reduction of thermal conductivity.

\subsection{Effect of tubes distance}

This section show effect of distance between tubes. For that, it has been choiced the next case: cycle of $24 \mathrm{~h}(8 \mathrm{~h}$ of charge and 16 hours of discharge), 10\% of PCM dosage and $40^{\circ} \mathrm{C}$ of inlet temperature.

An increase in distance between tubes implies a slight decrease in stored heat. Figure 10 shows this result.

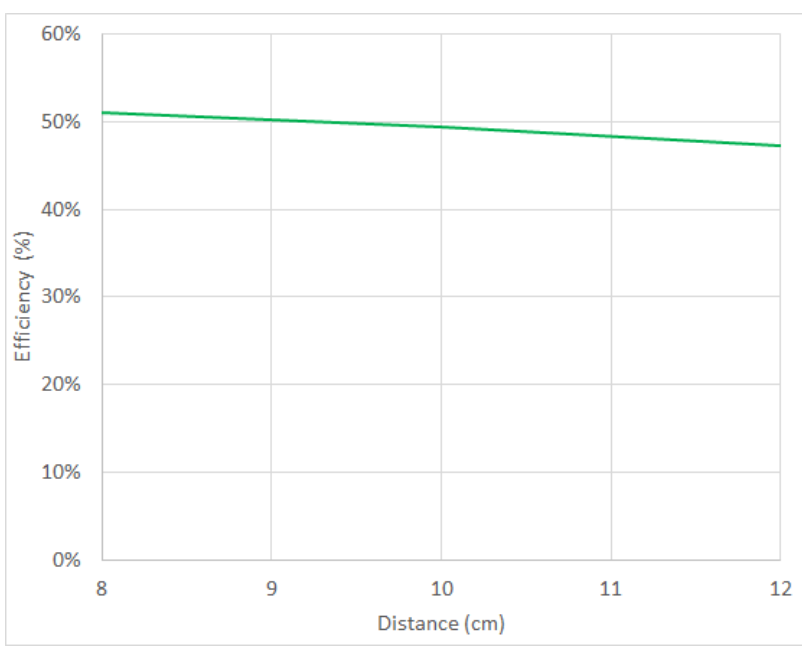

Fig. 11. Variation of efficiency in function of distance between tubes

According figure 11, a efficiency reduction of $6 \%$ is observed by increasing distance from $8 \mathrm{~cm}$ to $12 \mathrm{~cm}$.

\subsection{Effect of discharge period duration}

The following study aims to analyze influence of activation system versus effective activation for expotaitation of phase change materials. But, it has to avoid high cost Solutions or forced vents. That is to say, how it is posible to maximize exploitation of solution.

However, it also shows the need to provide adequate control in the operation of the system to maximize the exploitation of the advantages of the latent energy stored by the PCM material.

As shown in Figure 12, an increase in charge period from 6 to $8 \mathrm{~h}$ does not imply changes in efficiency. However, after $8 \mathrm{~h}$, an increase in charging time implies a slight reduction in stored heat and a reduction in charging efficiency of approximately $5 \%$ from 8 to $12 \mathrm{~h}$.

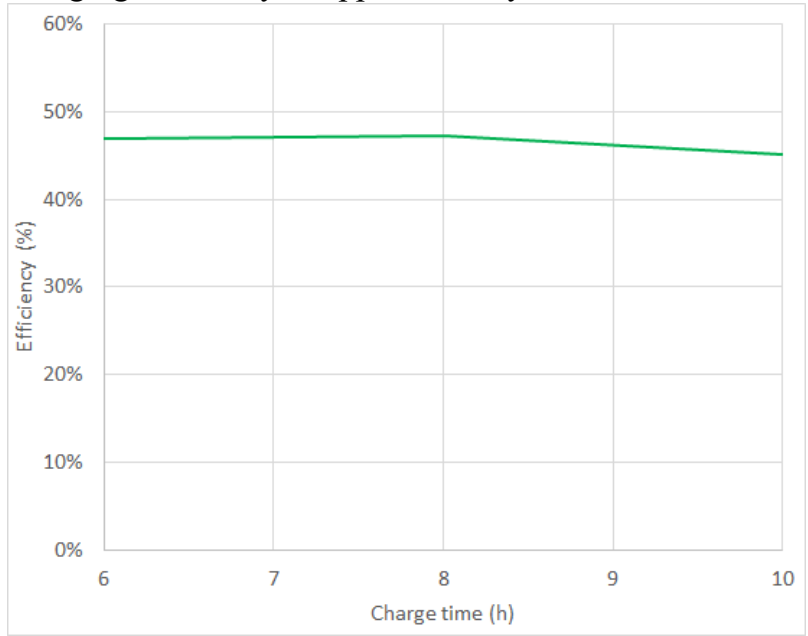

Fig. 12. Variation of efficiency in function of duration charge period.

Next paragraph analyses one charge per two days. The need for this study is linked to knowing how the TABS operating parameters vary if it is loaded from a removable source of the day. Besides, it supports the detected result in figure 9. 
The influence of cycle duration for a constant load of 8 hours is shown below. Case 1D (figures 12, 13, 14 and 15) represents the case of a cycle of $24 \mathrm{~h}$ ( $8 \mathrm{~h}$ charge and 16 hours of discharge) and 2D a cycle of $48 \mathrm{~h}$ ( $8 \mathrm{~h}$ charge and 40 hours of discharge).

Figures 13, 14, 15 and 16 show an increment of efficiency of $20 \%$ when duration of cycle is two days (one charge by two days).

This is due to explotaition of PCM latent energy (full solidification during discharge period). Because it is possible to use latent energy in two-day cycles, since temperatures are reached at the end of the discharge / load start of $21.4^{\circ} \mathrm{C}$.

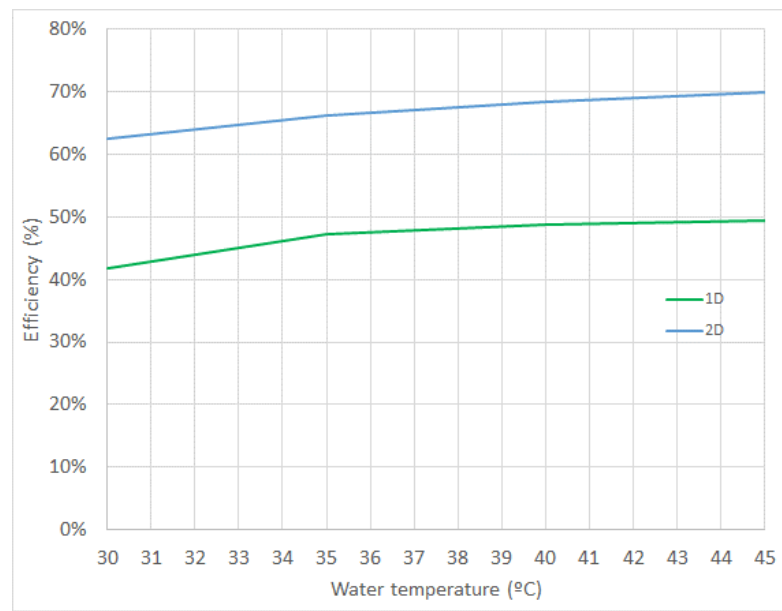

Fig. 13. Variation of efficiency in function of inlet water temperature - Cycle 2D

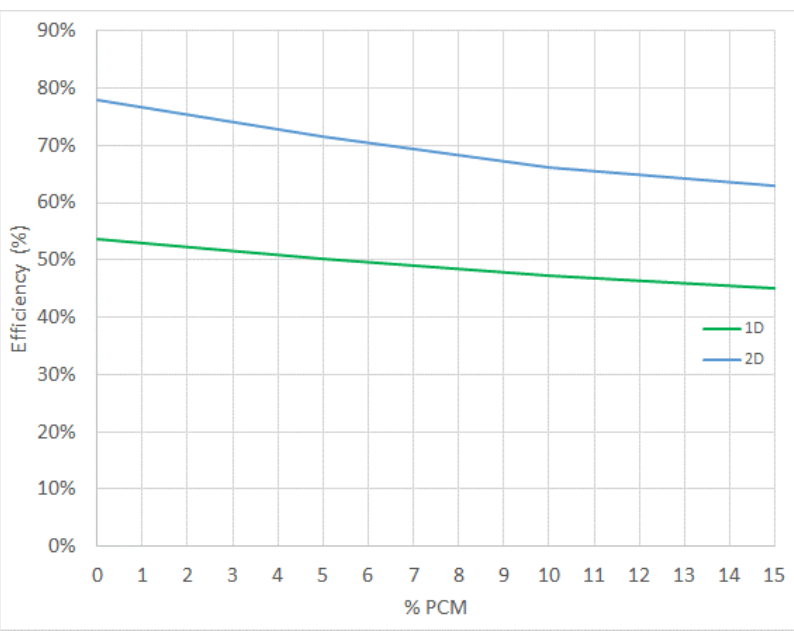

Fig. 14. Variation of efficiency in function of \% dosage of PCM - Cycle 2D

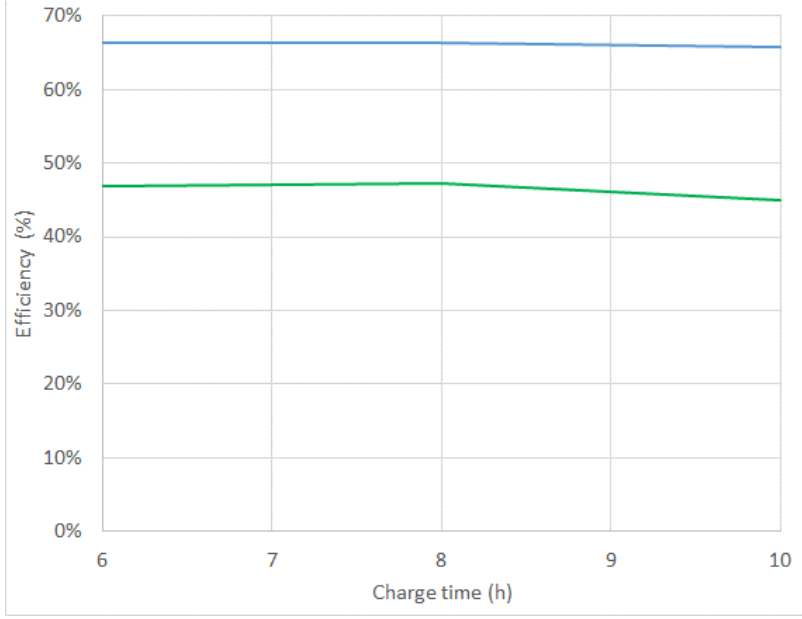

Fig. 15. Variation of efficiency in function of duration charge period - Cycle 2D

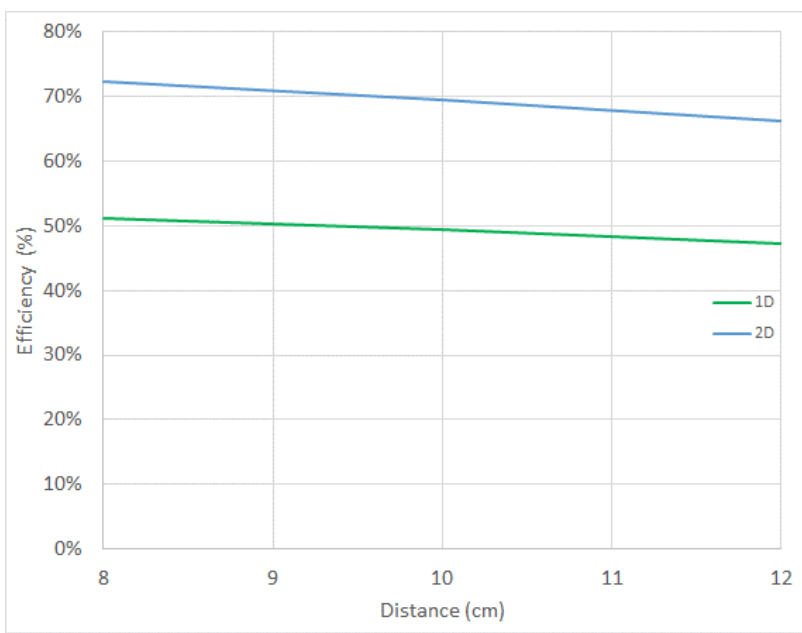

Fig. 16. Variation of efficiency in function of distance between tubes - Cycle 2D

\section{Application: use of performance tables}

The CFD methodology used has allowed characterization of the TABS solution proposed based on an efficiency parameter. This parameter of efficiency allows to know heat released by element towards indoor space. Then, indoor temperature can be obtained from this heat of conditioning. For this purpose, method proposed by Julián et al [17].

Figure 16 shows an example of a residential dwellings located in Seville. For this purpose, the coefficients of models have been previously identified using simulation data, as explained in the aforementioned article [17].

To obtain heat provided by the solution, a water temperature of $35^{\circ} \mathrm{C}$ has been assumed during a period of variable loading. This charging period has been characterized through simplified simulation of a low temperature solar thermal installation using the fchart methodology on a daily basis [18].

The evolution of temperature in free running conditions (indoor air temperature - orange in figure 17) is obtained from simulation. Furthermore, figure 17 shows heat 
discharged into space by the inphase solution (yellow), outdoor temperature (green) and resulting indoor temperature (blue).

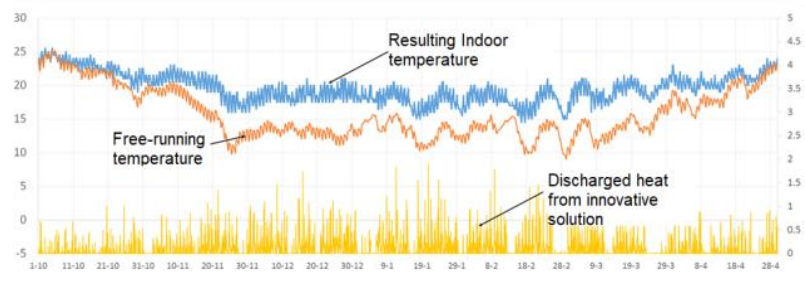

Fig. 17. Example of application

These results have allowed to characterize the solution with a regenerative exchanger efficiency. From it, it is possible to obtain heat that would be discharged into the air of the adjoining space, and therefore be able to relate it to the reduction of consumption. This simplified efficiency model is dependent on design parameters of the exchanger and operating parameters with which the cycle is operated.

Finally, the new comfort indicators can be obtained in the dwelling or, failing that, and as has been said, the obtained savings achieved.

\section{Conclusions}

Thanks to the results obtained, following considerations can be outlined for future design and implementation of this solution:

- Due to insulation of building, interior temperatures of solution are very similar to indoor setpoint temperatures.

- Optimal design of solution depends of meteorological conditions. Then:

- If it is designed for winter (phase change temperatura around $24^{\circ} \mathrm{C}$ ) and it is going to use it in summer in dissipation mode, PCM would only have sensible heat.

- If it is designed for summer (phase change temperature around $20^{\circ} \mathrm{C}$ ), it would only takes sensible contritubion of PCM during winter.

- It shows that additional cost involved increment of PCM dosage is not interesenting. It is due to low use of latent energy in daily cycles.

- Cycles of duration greater than one day reduce dependence on renewable resources.

- The dosage of PCM in the mortar is interesting in cycles over one day. In view of the results, good design must take into account points before.

Currently, experimental prototypes are being worked on through which to validate the results presented in this publication.

\section{Acknoledgments}

The authors would like to take this opportunity to thank the DACAR project "Zero-Energy Balance Districts Through Algorithms of Adaptive Comfort and Optimal Management of Energy Networks" (BIA2016-77431C2-2-R) funded by Ministry of Economy and Competitiveness (Government of Spain) and European Regional Development's funds (ERDF) for its partial support. The authors also thank the University of Seville for its financial support through the US Research Plan VI (VPPI-US).

\section{References}

[1] IEA, "Global Energy and CO2 Status Report 2017," Glob. Energy CO2 Status Rep. 2017, no. March, 2017.

[2] P. Arce, C. Castellón, A. Castell, and L. F. Cabeza, "Use of microencapsulated PCM in buildings and the effect of adding awnings," Energy Build., vol. 44, no. 1, pp. 88-93, 2012.

[3] J. Heier, C. Bales, and V. Martin, "Combining thermal energy storage with buildings - a review," Renew. Sustain. Energy Rev., vol. 42, pp. 1305-1325, 2015.

[4] J. Romaní, M. Belusko, A. Alemu, L. F. Cabeza, A. de Gracia, and F. Bruno, "Optimization of deterministic controls for a cooling radiant wall coupled to a PV array," Appl. Energy, vol. 229, no. August, pp. 1103-1110, 2018.

[5] J. Romani, G. Perez, and A. de Gracia, "Experimental evaluation of a heating radiant wall coupled to a ground source heat pump," Renew. Energy, vol. 105, pp. 520-529, 2017.

[6] S. Verbeke and A. Audenaert, "Thermal inertia in buildings: A review of impacts across climate and building use," Renew. Sustain. Energy Rev., vol. 82, no. September 2017, pp. 2300-2318, 2018.

[7] T. Q. Péan, J. Salom, and R. Costa-Castelló, "Review of control strategies for improving the energy flexibility provided by heat pump systems in buildings," J. Process Control, Apr. 2018.

[8] J. Le Dréau and P. Heiselberg, "Energy flexibility of residential buildings using short term heat storage in the thermal mass," Energy, vol. 111, pp. 991-1002, 2016.

[9] A. Arteconi, D. Patteeuw, K. Bruninx, E. Delarue, W. D'haeseleer, and L. Helsen, "Active demand response with electric heating systems: Impact of market penetration," Appl. Energy, vol. 177, pp. 636-648, Sep. 2016.

[10] D. Saelens, W. Parys, and R. Baetens, "Energy and comfort performance of thermally activated building systems including occupant behavior," Build. Environ., vol. 46, no. 4, pp. 835-848, 2011.

[11] S. P. Corgnati and A. Kindinis, "Thermal mass activation by hollow core slab coupled with night ventilation to reduce summer cooling loads," Build. Environ., vol. 42, no. 9, pp. 32853297, 2007.

[12] G. P. Henze, C. Felsmann, D. E. Kalz, and S. Herkel, "Primary energy and comfort performance of ventilation assisted thermoactive building systems in continental climates," Energy Build., vol. 40, no. 2, pp. 99-111, 2008.

[13] G. Salvalai, J. Pfafferott, and M. M. Sesana, "Assessing energy and thermal comfort of 
different low-energy cooling concepts for nonresidential buildings," Energy Convers. Manag., vol. 76, pp. 332-341, 2013.

[14] "CATIA ${ }^{\mathrm{TM}}$ 3DEXPERIENCE® - Dassault Systèmes ${ }^{\circledR}$ 3D Software.”.

[15] "Engineering Simulation \&amp; 3D Design Software | ANSYS.”.

[16] P. Lamberg and K. Sirén, "Approximate analytical model for solidification in a finite PCM storage with internal fins," Appl. Math. Model., vol. 27, no. 7, pp. 491-513, 2003.

[17] J. A. Díaz, J. S. Ramos, M. C. G. Delgado, D. H. García, F. G. Montoya, and S. Á. Domínguez, "A daily baseline model based on transfer functions for the verification of energy saving. A case study of the administration room at the Palacio de la Madraza, Granada," Appl. Energy, vol. 224, pp. 538-549, Aug. 2018.

[18] "EES: Engineering Equation Solver | F-Chart Software : Engineering Software.”. 